abnormalities which suggest dysmorphogenesis may justify obtaining the advice of a clinical geneticist. In $50 \%$ of people with mental retardation the cause is uncertain and dysmorphic features could become increasingly relevant as clinical genetics develops and advances.

It is fashionable now for mentally retarded people to have "individual programme plans", IPPs. A complementary medical "individual physical (or somatic) profile" could be proposed as an essential part of the holistic appraisal of these people.

DOuglas A. SPEnCER

Meanwood Park Hospital

Leeds LS6 4QB

\section{The moral case against psychotherapy}

\section{DeAR SiRS}

Dr Charlton's paper (Psychiatric Bulletin, 1991, 15, 490-492) was an interesting account of his opinions regarding psychotherapy. However, it was a confused and confusing article. Confused because he has a fundamentally incorrect understanding of the basic principles of psychotherapeutic treatments. Confusing because in applying his arguments, he fails to make the distinction between the various forms of psychotherapy. Presumably his criticisms were levelled at dynamic psychotherapy and it is to this area that the following comments are addressed.

Perhaps a better definition than the one given would be: psychotherapy is what happens when a doctor listens to a patient. It is not meant to be "edifying conversation". Although dependent on the interaction of two people, the passage of intimate, personal details is from patient to doctor. As such, the psychotherapeutic relationship is unique, allowing for the amplification of transference phenomenon which occur. The process of effecting change in the individual (one of the main aims of dynamic psychotherapy) can be painful, disquieting and anxiety-provoking for the patient, and he needs to work hard both within and between sessions to do it successfully. This experience can be far from edifying.

Dr Charlton sees it as a surrender of autonomy. This is a false conclusion. A further aim of dynamic psychotherapy is the enhancement of autonomy. The patient is not given the answers to his problems, it is a means whereby he can clarify the causation and current status of his difficulties in order to find a solution for himself. It is the person himself who chooses to medicalise his problems. Such is his right if his autonomy is to be respected.

Psychotherapists do not claim to be experts at talking to people about their lives. Neither are they trained to practise their jobs professionally and efficiently. Their reasons for choosing this particular job is beyond the scope of this discussion.
No-one is claiming that psychotherapy is the universal panacea for all emotional problems - to do so would be as foolish as claiming it to be morally depraved. However with careful selection of patients, it has been shown to be an effective treatment (Luborsky et al, 1975; Smith \& Glass, 1977).

Finally, psychotherapy is a difficult and demanding occupation. Perhaps a more appropriate warning to its adherents would be that contained in the words of Nietzsche: "He who fights with monsters should look to it that he himself does not become a monster. And when you gaze long into an abyss the abyss also gazes into you" (Nietzsche, 1972).

T. N. Evans

A. IWANCZYK

H. M. JONES

Cefn Coed Hospital

Cockett, Swansea

West Glamorgan SA8 3HR

\section{References}

LUBorsky, L., Singer, B. \& LUBORSKy, L. (1975) Comparative studies of psychotherapies. Archives of General Psychiatry, 31, 995-1008.

NietZSCHE, F. (1972) Beyond Good and Evil. Penguin

SMITH, M. L. \& Glass, G. V. (1977) Meta-analysis of psychotherapy outcome studies. American Psychologist, $32,752-760$.

\section{DeAR SiRs}

I am accused both of creating confusion and myself being confused. This might be a more compelling argument if the field of psychotherapy possessed anything approaching clarity or precision: it does not. There are no "basic principles of psychotherapeutic treatments", but almost as many principles as there are therapists (presumably because these "principles" are based upon pure theory with no means of discriminating between them except by what takes your personal fancy). It therefore becomes a pointless exercise to "make the distinction between the various forms of psychotherapy".

For proof we need look no further than the metaanalyses of Smith \& Glass (1977) and Luborsky et al (1975) which Evans et al cite with approval. I personally consider such meta-analytical techniques to be highly dubious - or at least very prone to mislead - but nevertheless let us consider their conclusions. First of all, they report that psychotherapy is better than no treatment: in other words they have rediscovered the placebo effect. But secondly they report "negligible differences in the effects produced by ten different therapy types" (Smith \& Glass) and "insignificant differences between therapy types in proportions of patients who improved" (Luborsky et al). Also, Smith \& Glass showed no differences in outcome according to the length of "training" of the 
therapist, although Luborsky et al assume without checking that inexperienced therapists were worse. Also, no benefit of longer over shorter treatment. Altogether, an impressive series of negatives.

Anyway, the majority of studies included in these analyses defined success as based on the therapist's own judgement. Apparently psychotherapists are excused not only from placebo controlled studies, but also from double-blinding! When Harty \& Horvitz (1976) compared therapists, patients and research judge's ratings of the benefit of psychotherapy, the therapists always rate their outcomes as more successful than either the patient or the outside observer (this applied particularly strongly to psychoanalysis where judges gave only a $20 \%$ success rate after a median of 540 treatment sessions!)

The definition of psychotherapy as doctors listening to patients is one which is specific to certain dynamic psychotherapies. Nevertheless, I had always supposed that the dynamic therapist did indeed speak from time to time: using words of greatly enhanced impact due to being so sparingly employed. But this definition does not begin to cover the scope of techniques included in the meta-analytical studies, nor the even larger range of counselling and psychotherapies which are actually practiced under those names. Highminded comments outlining the "aims" of dynamic psychotherapy are all very pleasant, but so what? Everybody (excepting a few evil geniuses) "aims" to help unhappy folk, enhance their autonomy and all the rest of it. The whole point at issue is whether or not psychotherapy actually delivers what it promises.

Nietzsche attempted (among many other things) the unmasking of, for example, Christianity; saying that the actual effect of a doctrine may be exactly contrary to its self-advertised "aims". My argument with psychotherapy is analogous. In the first place I have tried to demonstrate that the "unmasked" effect of psychotherapy is often morally bad rather than good; in the second place (and given that psychotherapy may be unavoidable) that there is no justification for professionalising the activity.

If psychotherapists "do not claim ..." to be experts, then what is their justification, why do they exist at all? In any case, whatever their "claims", objective evidence of therapeutic expertise is lacking; expertise at theory is another matter altogether. It is not sufficient for professionals to wring their hands modestly and emphasise how difficult their job is; when the very points at issue are the value and effectiveness of what they are doing.

The psychotherapist's status and/or livelihood should not depend on attracting and maintaining a set of clients to practice upon. A network of amateurs and part-timers doing psychotherapy as a sideline would effectively fill any gaps left by family, friends and aquaintances: who are and should remain the first-line helpers when life gets tough.

Department of Anatomy

Bruce G. Charlton

The University

Glasgow G12 8QQ

\section{References}

HARTY, M. \& HoRvitz, L. (1976) Therapeutic outcomes as rated by patients, therapists, and judges. Archives of General Psychiatry, 33, 957-961.

Luborsky, L., Singer, B. \& Luborsky, L. (1975) Comparative studies of psychotherapies. Archives of General Psychiatry, 32, 995-1008.

SMith, M. L. \& Glass, G. V. (1977) Meta-analysis of psychotherapy outcome studies. American Psychologist, 32, 752-760.

\section{DeAR SiRs}

I must confess, after going through the whole-hearted correspondence (Psychiatric Bulletin, 1991, 15, 770 774 in response to Bruce Charlton's article on 'The Moral Case against Psychotherapy' (Psychiatric Bulletin, 15, 490-492), I had to go back to the article once again to see why and what in that article, which was only a "personal view", invited such a response from the respondents who presumably practise psychiatry. Some even questioned Dr Charlton's right to put down a personal view and the editorial's acceptance for its publication.

Charlton's article, on the other hand, was a timely stimulus for introspection and raised very important issues regarding training, practice and future of psychotherapy specially for the changing 'new look' NHS.

Whereas the respondents were quick to appreciate that Bruce Charlton failed to differentially analyse types of psychotherapy and lumped all of them together under an umbrella term "psychotherapy", amusingly they too did not fare better on that count. Thanks to half a century of interest by professionals from diverse specialities starting with Freud's psychoanalysis at the beginning of this century, the theoretical orientation and practice of psychotherapy has changed dramatically (Arya, 1991). Moreover, in the last $\mathbf{4 0}$ years psychopharmacology has threatened its survival which has necessitated emergence of many new and diverse forms of psychotherapies. Fortunately or unfortunately, neither of the two disciplines (psychopharmacology and psychotherapy) could convincingly prove to be based on a definite aetiological hypothesis. The clash of interests has to continue and only articles of critique (like Charlton's) can make us practise with awareness of this deficiency in our limited repertoire of knowledge about what we recognise as psychiatric ailments.

Charlton's article raised some very important questions. Is the training of juniors in psychotherapy 